\title{
Editorial
}

\section{Enfermagem, saúde mental e atenção básica: reconstruindo cenários, ressignificando vidas}

\author{
Jacileide Guimarães*
}

Desde o final da década de 1970, a assistência psiquiátrica e de saúde mental brasileira busca concretizar novas formas de lidar com o sofrimento psíquico ou doença mental. Isso vem se dando com o processo de Reforma Psiquiátrica brasileira deflagrado em 1978 sob o lema "Por uma sociedade sem manicômios”. Assim, surgem novas propostas de acolhimento, atendimento e assistência ao sofrimento psíquico.

Em termos legislativos foi aprovada em 06 de abril de 2001 a Lei da Reforma Psiquiátrica brasileira que vinha sendo discutida desde 1989. Leis estaduais e municipais também foram aprovadas em todo o país, além de Portarias Federais que dispóem sobre a orientação e fiscalização dos novos serviços em saúde mental no Brasil [1].

Já em termos assistenciais, foram criados os novos serviços em saúde mental, cuja finalidade é substituir a forma de assistência hospitalocêntrica por serviços de base territorial. Assim são os Centros de Atençáo Psicossocial (Caps) existentes em todo o território brasileiro onde tem sido reduzido o número de leitos em hospitais psiquiátricos. Até junho do ano corrente o Brasil dispunha de 1.394 Caps presentes em todo o país, porém, de acordo com parâmetros do Ministério da Saúde em termos de cobertura por unidade federativa, apenas seis estados apresentam uma cobertura considerada muito boa, embora devamos ressaltar que em três deles não há Caps III, o que nos instiga aos seguintes questionamentos: onde estáo sendo acompanhadas as pessoas que necessitam tempo- rariamente de internaçáo? Estariam essas pessoas sendo internadas em hospitais psiquiátricos remanescentes ou clínicas psiquiátricas conveniadas ao SUS? Pois, se isso acontece, podemos inferir que os avanços são palpáveis, mas, a luta por uma sociedade sem manicômios é uma conquista que se constrói diariamente, desconstruindo-se uma lógica de estigmatização e exclusão social, historicamente reconhecida como iatrogênica [2-4].

Outra conquista do processo de Reforma Psiquiátrica brasileira tem sido a aproximação da saúde mental com a atenção básica. Isso vem favorecer os três níveis de atenção: atenção primária, secundária e terciária, uma vez que a identificação de casos e o diagnóstico precoce aumentam com a presença dos conhecimentos da saúde mental em Estratégias de Saúde da Família (ESF), através do diálogo do apoio matricial em saúde mental. $\mathrm{O}$ apoio matricial da saúde mental às equipes da atenção básica constitui um diálogo entre os serviços, onde a equipe de profissionais da ESF compartilha com a equipe do Caps os casos clínicos de pessoas com sofrimento mental em sua área de abrangência, esse compartilhamento produz a co-responsabilização das equipes envolvidas e contribui para a redução da lógica do encaminhamento fragmentado, aumentando a capacidade de resolução de problemas de saúde pela equipe local e a ampliação do acolhimento, do tratamento e do acompanhamento dos usuários. Isso contribui para a integralidade dos serviços de saúde, das ações e intervençóes dos profissionais e, especial- 
mente, para a integralidade do estado clínico físico e mental do usuário dos serviços $[5,6]$.

O profissional de enfermagem - assim como os demais profissionais da equipe de saúde mental - possui a atribuição principal de ser um cuidador em saúde mental, isto inclui desde a competência técnica específica até a promoção de estratégias de valorização da auto-estima e reinserção social da pessoa com transtorno psiquiátrico. Implica ainda a compreensão ética de participação no processo da mudança do atendimento hospitalocêntrico para um acolhimento comunitário. A noção de cidadania vem demarcar o eixo principal das novas formas de assistência porque traz consigo os fatores de inclusão social e ampliaçáo do poder de contratualidade da pessoa com sofrimento psíquico. Sendo que a inclusão social diz respeito à reinserção no meio da sociedade da pessoa excluída pelos longos anos de internaçáo em instituições psiquiátricas e, a ampliação do seu poder de contratualidade refere-se à criação de estratégias de valorização da pessoa a partir do fortalecimento de seus níveis de autonomia cotidiana através das atividades da vida diária (AVD).

O saber/fazer da Enfermagem Psiquiátrica compreende a aprendizagem, o ensino, a pesquisa e o cuidado, na mediaçáo do processo de comunicação humana que envolve profissional, usuário do serviço e familiares, com o propósito de contribuir para a melhor qualidade de vida da pessoa com sofrimento psíquico, incluindo o resgate de sua cidadania. Assim, trata-se agora em uma perspectiva histórica e contemporânea - da Enfermagem Psiquiátrica, Saúde Mental e Atenção Psicossocial. A rede de atenção à saúde mental amplia o seu alcance ao romper o estigma da exclusão, especialmente, através da sua inserção na atenção básica, com isso, reconstrói cenários, abrangendo a sua maior conquista, da qual a equipe de enfermagem - enfermeiros, técnicos e auxiliares - participam efetivamente ao contribuir através do seu exercício profissional para a ressignificação de vidas historicamente excluídas.
Nessa perspectiva o 20 SENABS - Seminário Nacional de Diretrizes para Enfermagem na Atenção Básica em Saúde - promovido pela Associação Brasileira de Enfermagem, seção Pernambuco, realizado de 20 a 22 de agosto no Recife, traz como tema central a " $(\mathrm{Re})$ construção de Cenários na Atenção Básica em Saúde”. A relevância de um seminário de diretrizes em escala nacional atesta, por si, a premência e importância da temática central escolhida, tanto no âmbito restrito da categoria profissional quanto no campo amplo da saúde brasileira [7]. Assim, a enfermagem brasileira como prática social articulada aos princípios e diretrizes do Sistema Único de Saúde consolida caminhos em busca de atualização coerente com as conquistas advindas da Reforma Sanitária, pautada em mudanças pela democratização participativa do setor saúde no Brasil.

\section{Referências}

1. Brasil. Ministério da Saúde. Secretaria de Atenção à Saúde. Legislação em saúde mental: 1990-2004. $5^{a}$ ed. ampl. Brasília: Ministério da Saúde; 2004.

2. Saúde Mental em dados. [citado 2009 Jul 31]. Disponível em: URL: http://portal.saude.gov.br/saude/ saudemental

3. Amarante P, Ed. Loucos pela vida: a trajetória da reforma psiquiátrica no Brasil. 2a ed. Rio de Janeiro: Fiocruz; 1994.

4. Amarante P. Psiquiatria social e reforma psiquiátrica. Rio de Janeiro: Fiocruz; 1994.

5. Brasil. Ministério da Saúde. Secretaria de Atenção à Saúde. Departamento de Açóes Programáticas Estratégicas. Saúde mental no SUS: os centros de atenção psicossocial. Brasília: Ministério da Saúde; 2004.

6. Brasil. Ministério da Saúde. Secretaria de Atenção à Saúde. Departamento de Açóes Programáticas Estratégicas. Saúde Mental no SUS: acesso ao tratamento e mudança do modelo de atenção. Relatório de Gestão 2003 -2006. Ministério da Saúde: Brasília; 2007.

7. 2o SENABS - Seminário Nacional de Diretrizes para Enfermagem na Atenção Básica em Saúde - Associação Brasileira de Enfermagem. "(Re)construção de Cenários na Atenção Básica em Saúde”. 20, 21 e 22 de agosto de 2009. Recife-PE. [citado 2009 Jul 31]. Disponível em: URL: http://www.abeneventos.com. br/SENABS/seminario.html 